\title{
Das vizinhanças entre o feminino e a loucura
}

\author{
Elizabeth Cristina Landi*1 \\ Isalena Santos Carvalho*2 \\ Daniela Sheinkman Chatelard*3
}

O tema da loucura feminina se apresenta frequentemente na clínica psicanalítica por meio de sujeitos neuróticos. Questiona-se neste artigo as proximidades entre psicose e a loucura que se apresenta no discurso das mulheres neuróticas. As identificações iniciais, por meio das quais a criança se aliena ao desejo do Outro, determinam certa loucura, não restrita apenas aos psicóticos. Para um sujeito do sexo feminino, que passa pelo tortuoso processo de tornar-se mulher, a loucura é uma possibilidade, pois uma mulher, por encontrar-se dividida entre o gozo masculino e o feminino, se aproxima da loucura, mas é não louca-de-todo.

Palavras-chave: Loucura feminina, psicose, gozo fálico, gozo feminino

${ }^{* 1}$ Universidade Federal de Goiás (Goiânia, GO, Br).

*2 Universidade Federal do Maranhão (São Luiz, MA, Br).

*3 Universidade de Brasília - UnB (Brasília, DF, Br) 
$\mathrm{Na}$ clínica psicanalítica, frequentada abundantemente por sujeitos do sexo feminino, estruturalmente neuróticos, é comum as analisantes tratarem do tema da loucura. Ora ressentem-se de não tê-la cometido, ora culpabilizam-se por se deixarem levar por ela, ora enlouquecem e disso gozam, sendo atravessadas por um pathos que as coloca na excentricidade própria ao inconsciente. Sendo a loucura um significante tão presente nas associações de analisantes neuróticas, bem como circunscrito ao campo das psicoses, questiona-se neste artigo a vizinhança que parece se evidenciar entre psicose e a loucura que se faz presente no discurso das mulheres neuróticas. Haveria uma loucura própria às mulheres, aquelas para quem o registro civil reserva o sexo feminino, que pontualmente se confessam loucas ou desejosas de sê-lo, ainda que não se estruturem na psicose?

Para iniciar a discussão acerca desses questionamentos, faz-se necessário estabelecer uma distinção fundamental: o que estrutura a psicose não estrutura a neurose, uma vez que o modo de defesa privilegiado da neurose é o recalque, e da psicose a foraclusão. Freud (1924/2007a) esclarece o ponto de divisão e, consequentemente, de diferenciação entre uma estrutura e outra: na neurose, o recalque divide o sujeito colocando-o numa situação de conflito psíquico, entre o Eu e o Isso, produzindo o sintoma neurótico como resultado, enquanto na psicose o conflito se situa entre o Eu e o mundo externo, produzindo uma fenda que será alvo de uma tentativa de remendo pelas formações delirantes (Freud, 1924/2007a).

Lacan (1955-1956/2002), extrai do texto freudiano o termo Verwerfung (foraclusão), operador estrutural da psicose: "trata-se da rejeição de um significante primordial em trevas exteriores [...]. Trata-se de um processo primordial de exclusão de um dentro primitivo, que não é o dentro do corpo, mas aquele de um primeiro corpo de significante" (p. 174). Esse significante primordial pode ser simbolizado por meio da Bejahung primitiva, isto é, da afirmação inaugural que constitui a realidade psíquica, fazendo o sujeito compor o mundo, situar-se nele, inclusive denegando (Verneinung) o significante, o que será sinal de que o mesmo já fora inscrito pela afirmação (Bejahung). Porém, a foraclusão implica justamente que algo não foi simbolizado, não pôde compor o 


\section{ARTIGOS}

corpo de significante nas origens da relação do sujeito com o símbolo, provocando a fenda entre o Eu e o mundo externo de que fala Freud.

A foraclusão do significante comparece justo no ponto em que o Nome-do-Pai não responde por carecer do efeito metafórico, provocando um furo no lugar da significação fálica (Lacan, 1959/1998b). O Nome-do-Pai é o significante responsável por engenderar a significação fálica, uma vez que por sua operação ele metaforiza o desejo da mãe, substituindo-o e protegendo o filho da invasão do gozo do Outro. É o significante que produz a metáfora paterna, ordena a cena do mundo, estabelecendo a ordem fálica que produzirá efeitos simbólicos. Na psicose, é o significante Nome-do-Pai que está foracluído, rejeitado no simbólico, produzindo como efeito seu retorno no real sob a forma de alucinações e delírios. A impossibilidade de barrar o gozo faz com que este se apresente sem a amarração simbólica que dá contorno ao real.

Já na neurose, a metáfora paterna opera produzindo as formações do inconsciente, bem como certa perda de realidade, uma vez que o recalque se encarrega de manter inconsciente as representações inconciliáveis (Freud, 1924/2007b). Mas a fantasia que retira parcialmente o neurótico da realidade não implica com a mesma potência a perda de realidade que leva o psicótico ao delírio, justamente porque o Nome-do-Pai produz efeitos de ordenamento simbólico que permite algum tipo de compartilhamento de significação que não é possível ao psicótico.

Apesar dessa diferença estrutural, não é incomum a presença de manifestações alucinatórias e delirantes nas neuroses, tanto histérica quanto obsessiva, como Freud (1893-1895/1976a; 1909/1976c) menciona no caso de Emmy Von N. e no caso do homem dos ratos. No entanto, não se trata do mesmo motivo estrutural, uma vez que nas neuroses o delírio comparece como fracasso da defesa e como fantasias que irrompem de maneira súbita e não são conscientes, tal como o que ocorre na paranoia (Freud, 1908/1976b). A participação delirante na determinação dos sintomas não é a mesma que na psicose, em que o delírio é remendo que tenta costurar o que foi rasgado. Assim, manifestações sintomáticas de loucura não são características que denunciam uma estrutura psicótica ou neurótica.

Ao recolocar a questão da loucura no âmbito da psicanálise, em contraposição à psiquiatria da época, especialmente em seu diálogo com Henri Ey, Lacan (1946/1998a) enfatiza o problema do desconhecimento próprio à loucura, uma vez que "o louco se acredita diferente de quem é" (p. 171), o que pode ser constatado especialmente nos delírios megalomaníacos dos psicóticos. Essa alienação própria ao louco não é privilégio apenas dos que se estruturam a partir da foraclusão do Nome-do-Pai, uma vez que todo falante é alienado, 
desde o princípio da vida, ao desejo do Outro, sendo esta a estrutura fundamental da loucura. "As primeiras escolhas identificatórias da criança, escolhas "inocentes", não determinam outra coisa com efeito - à parte as patéticas "fixações" da neurose - senão essa loucura pela qual o homem se crê homem" (p. 189). As identificações iniciais, por meio das quais a criança se aliena ao desejo do Outro, determinam a loucura do homem, sua paixão narcísica. É somente com a metáfora paterna que alguma diferença poderá ser erigida.

A posição radical inaugurada por Freud e desenvolvida pelo ensino de Lacan situa de modo absolutamente diverso toda a construção acerca da normalidade e da patologia, fazendo com que a loucura seja parte intrínseca da constituição de todo falante. Assim, Lacan brilhantemente esclarece:

E o ser do homem não apenas não pode ser compreendido sem a loucura, como não seria o ser do homem se não trouxesse em si a loucura como limite de sua liberdade. [...] é realmente verdade que, como escrevêramos numa fórmula lapidar na parede de nossa sala de plantão "Não fica louco quem quer". Mas tampouco é quem quer que atinge os riscos que envolve a loucura. (p. 177)

Não se trata de um querer decidido a arriscar a loucura. Trata-se de um atravessamento de outra ordem, precisamente da ordem do inconsciente que joga a existência nos riscos da loucura. A causalidade da loucura está circunscrita "à insondável decisão do ser", o que Lacan (p. 179) formula como sendo a lei do devir, tal como a máxima do poeta Píndaro: Torna-te o que és! Tornar-se o que se é diz respeito a colocar em ato o que foi estruturado pelas vias identificatórias fundamentais, desde os tempos iniciais de encontro e desencontro do infans com o campo do Outro. Evidentemente a decisão do ser implica uma escolha que não é sondável, posto que se trata do inconsciente em potência de determinação. A cada um resta sofrer as marcas dessa decisão feita num tempo tão inaugural da constituição.

\section{Loucura feminina: que campo é esse?}

Se estruturalmente a alienação é constitutiva e a loucura é imanente a todo falante, como delimitar o campo da loucura que atravessa as mulheres estruturadas na neurose?

Freud (1931/1976f) tratou das mulheres desde o início da sua clínica, mas até o final abordou o tema como enigmático, apesar de ter deixado pistas que indicam o complicado processo de construção da feminilidade. Desde sua infância, as meninas constatam a inexistência do atributo fálico no próprio 


\section{ARTIGOS}

corpo e encontram um lugar no mundo a partir desse destino anatômico. Se Freud (1924/1976e) diz que a anatomia é o destino, podemos com Lacan (1962-1963/2005) entender o destino como desejo, uma vez que diante da impossibilidade de denegar as marcas anatômicas, as quais por meio do desejo do Outro produzirão efeitos simbólicos, resta recorrer à etimologia da palavra ana-tomia, que apresenta o corte no corpo produzido pelo Outro, campo simbólico de onde provém o significante. Desse corte resta o desejo. Assim, à anatomia está destinado o desejo, uma vez que o corpo será cortado pelo simbólico. Diante do destino anatômico que corta o corpo feminino, cada mulher terá de se ajeitar com a dupla falta que lhe atravessa.

Cada sujeito pertencente ao sexo feminino, ao longo de seu percurso para tornar-se mulher, se deparará com a falta estrutural que atravessa todo falante, inaugurando-o como sujeito de desejo. Como não existe o objeto que possa responder absolutamente à insistência pulsional, resta a falta, que promove o desejo. Diante desse impossível da satisfação, resta ao sujeito falar, desejar. Mas por pertencer a essa parte dos falantes que porta a outra marca, a presença fálica pelo negativo, isto é, sua ausência, uma mulher se situa diante da falta desse objeto simbólico do qual são privadas com a inveja do pênis. Não se trata do plano puramente imaginário, mas dos efeitos da "simbolização do objeto no real" (Lacan, 1956-1957/1995, p. 224).

É Freud (1924/1976e) quem conclui que na diferenciação dos sexos, a primazia não está nos órgãos genitais, mas no falo. É por isso que a única inscrição da diferença sexual se pauta neste significante que marca presença para uns e ausência para outros. Essa descoberta freudiana, que faz uma passagem do pênis imaginário ao falo simbólico, desloca radicalmente a sexualidade do lugar do corpo biológico, orgânico, para o âmbito da sua significação simbólica, o que situa ambos os sexos no âmbito da organização fálica.

São esses sujeitos, estruturalmente marcados pela falta-a-ser, que se apresentam na clínica colocando em pauta sua relação com a loucura. Uma analisante, estruturalmente neurótica, o que se pode deduzir a partir da transferência, dizia histericamente do convite que um parceiro lhe fez e que anos mais tarde ainda a acossava. "Ele me dizia que eu devia ser mais louca". Esse significante - louca - ressoou fortemente em seus ouvidos, fazendo-a falar na análise do seu desejo de ultrapassar os limites impostos pelo recalque, de sair do seu lugar cativo e ousar responder de um lugar diferente, louco, ao desejo do Outro. Do seu olhar limitado pela neurose, ela entrevê a liberdade que adviria de cometer as loucuras e, ao mesmo tempo, teme seus riscos, ficando por vezes dividida entre o arrependimento de conter-se e o desejo de entregar-se ao que lhe parece 
fora da lei que a atravessa. Se a loucura é o limite da liberdade para uns, para ela sua neurose a impedia de viver a liberdade de ser louca.

Outra analisante histérica, que temia fortemente seus desejos eróticos, chegando a produzir um vaginismo que a levou à análise, depois de muito atravessar seus ditos e enunciar seu posicionamento diante do Outro, começa a descobrir-se aberta ao desejo, mas chega a dizer: "Agora que sei que o desejo não é isso louco, desenfreado, preciso aprender a lidar com ele, não quero mandá-lo embora”. E se pergunta como fazer com isso, manter o desejo sem cometer as loucuras por ele incitadas, em sua fantasia. Abrir-se para o sexo seria loucura, mas ela começa a se dar conta de que não basta querer para ser louco, e que o sexo não é o desencadeador da loucura, visto que há um freio que o regula, efeito da operação do Nome-do-Pai.

Uma outra analisante ainda, enlouquecida de ciúmes, comete uma passagem ao ato, despenca fora da cena, caindo no "mundo, lugar onde o real se comprime", afastando-se da cena do Outro, onde "o sujeito [...] tem de assumir um lugar como portador da fala" (Lacan, 1962-1963/2005, p. 130). Desse lugar real, sem poder falar, ela passa ao ato. Só depois, na análise, pôde retomar a fala e dizer algo da queda: "Ele diz que eu sou louca, então sou mesmo!", reafirmando o gozo de ter sido ultrapassada pelo ato cometido, num ponto onde os limites da lei não puderam contê-la, fazendo-a entregar-se à loucura. Como não se trata de uma psicose, foi-lhe permitido reconhecer a loucura que lhe é própria, manifestada pontualmente.

Mesmo ancoradas na neurose, especificamente na histeria, cada uma dessas mulheres conta em sua análise seus flertes com o que é nomeado 'loucura', o que se avizinha da psicose por portar o risco de ultrapassar a regulação da lei. A loucura aqui é um significante que se apresenta na fala de cada uma, não diz respeito à produção da teoria psicanalítica. É da experiência de encontro com a loucura feita por cada sujeito e falada em análise, que esse artigo aborda a loucura feminina. Cada uma destas ilustrações clínicas refere-se a sujeitos neuróticos, que não têm manifestações delirantes ou alucinatórias, mas que desejam ou sofrem de loucura. Por tratar-se de neurose, para cada um desses sujeitos, pela metáfora paterna, está garantida uma amarração fálica, por efeito da operação do Nome-do-Pai (Lacan, 1957-1958/1999).

Considerando o significante 'loucura' tão recorrente nas falas das mulheres, é possível pensar que a loucura feminina seja relativa justamente ao tornar-se mulher? As descobertas freudianas acerca da sexualidade feminina mostram que tornar-se mulher não está dado a princípio, uma vez que inicialmente as crianças são regidas pela primazia fálica, funcionando 
como homenzinhos. Segundo Freud (1933[1932]/1976g), "as diferenças entre os sexos são completamente eclipsadas pelas suas semelhanças. Nisto somos obrigados a reconhecer que a menininha é um homenzinho" (p. 146). Se no primeiro tempo da sexualidade infantil a diferença sexual não se apresenta, por haver para ambos os sexos apenas o falo como referência, com a constatação da castração a menina poderá experimentar a transformação de seu próprio corpo, deixando de ser esse homenzinho ao descobrir na sensibilidade de outro órgão genital, ainda desconhecido, um modo de satisfação que prioriza a meta passiva rumo à feminilidade. Há, portanto, duplicidades no caminho da construção da feminilidade, envolvendo a identificação, a partir da mudança de zona erógena - do clitóris à vagina - , e a escolha objetal, a partir da mudança de objeto - que deixa de ser a mãe e passa a ser o pai.

$\mathrm{O}$ destino edipiano rumo à feminilidade é demorado e indireto (Freud, 1931/1976f; 1933[1932]/1976g). Tornar-se mulher é da ordem do mesmo devir expresso na fórmula mencionada por Lacan (1946/1998a): "Genoi, oíos essi" (Torna-te o que és) (p. 179). Como essa não é a única possibilidade destinada a uma menina, justamente pelo caminho tortuoso que ela percorrerá para tornar-se ou não mulher, o destino dependerá de como cada uma foi cortada e deixou-se cortar simbolicamente pelo Outro. É nesse tornar-se que se situa a causalidade da loucura, marcada por uma "insondável decisão do ser", da qual cada um participa, independentemente da estrutura ou do sexo ao qual pertence.

\section{Não todas, isto é, não loucas-de-todo}

Um outro caminho para investigar as vizinhanças entre loucura feminina e psicose pode ser encontrado nas elaborações feitas por Lacan (1972-1973/2008) mais ao final de seu ensino, quando, para tratar da diferença sexual, do que caracteriza o posicionamento sexual feminino e sua diferença em relação ao masculino, constrói as fórmulas da sexuação. Trata-se de uma abordagem que interroga os efeitos da diferença sexual nos sujeitos para além da distinção anatômica entre os sexos, questionando qualquer falante acerca da sua posição frente ao gozo. Para além da satisfação sexual, há algo da ordem de um gozo que se impõe a homens e mulheres, a partir de duas possibilidades: o gozo masculino e o feminino (Maurano, 2011).

Essa abordagem da duplicidade de gozos inicia-se uma década antes, quando Lacan (1960/1998c, p. 739) coloca em questão as saídas fálicas para a sexualidade feminina, tais como ser o falo para um homem ou ter um 'filho 
falo' como resposta à sua falta-a-ter, indagando se a "mediação fálica drena tudo o que pode se manifestar de pulsional na mulher". É nesse momento também que escuta Tirésias, o cego adivinho que por ter experimentado as duas condições em seu corpo, tendo sido homem e depois mulher, ao ser indagado revelou que as mulheres gozam mais. Lacan (1962-1963/2005) extrai desse sábio cego que vê longe, e que segundo ele deveria ser o padroeiro dos psicanalistas, uma indicação acerca do enigma feminino e sentencia:

A mulher revela-se superior no campo do gozo, uma vez que seu vínculo com o nó do desejo é bem mais frouxo. A falta, o sinal menos com que é marcada a função fálica no homem, é que faz com que sua ligação com o objeto tenha que passar pela negativação do falo e pelo complexo de castração, o status do $(-\varphi)$ no centro do desejo do homem, é isso que não constitui, para a mulher, o nó necessário. (p. 202)

A castração, responsável pela negativização do falo simbólico, empurra o homem rumo ao desejo, mas para a mulher o desejo comparece de outro modo, não todo gravitando em torno da castração. Seguindo a trilha freudiana, Lacan descobre mais uma duplicidade feminina, para além das já evidenciadas na divisão entre clitóris e vagina, mãe e pai como objetos de amor, que diz respeito ao que a divide entre um gozo referido ao falo e outro que a ele escapa.

Após esse momento, ao avançar nas elaborações rumo ao que não se circunscreve ao simbólico, aproxima-se do real e do campo do gozo, extraindo daí um saber sobre o feminino, do qual só pode se deduzir pelo que resta atravessado na pena dos poetas e dos místicos, e que não se atém aos sujeitos pertencentes anatomicamente ao sexo feminino. Para isso, recorre à lógica e à matemática, compatíveis com o discurso psicanalítico justamente porque atingem um real (Lacan,1972-1973/2008).

O desejo, fundado pelo significante fálico, insiste no sujeito, mais, ainda, no corpo. Não se trata do corpo das necessidades, mas do corpo atravessado, constituído pela linguagem, corpo pulsional, corpolinguagem. Esse corpo simbólico demanda satisfação insistentemente, pois o Outro, campo no qual o corpo se faz linguageiramente, falha. O Outro não contém todos os significantes que poderiam responder às necessidades do sujeito, o que o remete à castração e ao desejo. Do lugar de castrado, de falta-a-ser, resta ao falante desejar e essa operação desejante se faz pela via da linguagem, com o aparelho de gozo que é a linguagem. Esse campo do gozo na e da linguagem é fálico, pois se sustenta no significante. O masculino diz respeito a esse gozo linguageiro, que, "enquanto sexual, é fálico, quer dizer, ele não se relaciona ao Outro como tal" (Lacan, 1972-1973/2008, p. 15-16). 


\section{ARTIGOS}

O gozo fálico falha, porque falta algo à linguagem, que não recobre tudo, e como consequência disso a relação sexual, a ligação entre um sexo e outro, rateia e se apresenta na sua face impossível. Portanto, o gozo fálico não se sustenta infalível, o que remete logicamente ao seu avesso, o não todo fálico. Há, então, dois modos de se colocar na linguagem: o todo e o não todo, sendo este último próprio ao campo do feminino. A oposição todo/não todo indica a impossibilidade de haver completude, pois o não todo não faz o Um da relação sexual, suposto consistir do lado do todo masculino. Daí a afirmação lacaniana acerca da inexistência da relação sexual, que possibilitaria a complementaridade (Lacan, 1972-1973/2008).

Do lado masculino das fórmulas da sexuação, situa-se o todo, referido ao gozo fálico, que é narcísico por não se relacionar com a diferença do Outro. $\mathrm{Na}$ medida em que é esse o gozo que não necessita do Outro, é o gozo do Um, pautado no falo enquanto significante da falta (Lacan, 1972-1973/2008). Parece haver uma busca insistente de encontrar o objeto e fazer da falha o acabamento do todo, pela via da significação fálica. No entanto, por oposição ao todo fálico, a partir do lado feminino é que pode ser elaborada a impossibilidade da relação sexual, uma vez que é este o campo do não todo.

Lacan (1972-1973/2008) propõe que esse gozo do sentido, da linguagem, é da ordem do necessário, pois não cessa de se escrever, diz respeito ao que insiste em ser simbolizado. Não é possível ser falante e não se submeter a esse império da palavra, daí o gozo fálico se inscrever no âmbito do necessário, porque a linguagem é insistente. Essa insistência de escrita se faz sobre o real que é da ordem do impossível, pois não cessa de não se escrever, está fora do campo da linguagem. Diante de um real ao qual nada falta, que se apresenta como não escrito, incide o simbólico, numa tentativa de torná-lo possível pela via da linguagem. Articulado com o impossível de simbolização, o real é o que se apresenta do lado feminino, uma vez que neste campo algo permanece irrepresentável, o que Lacan (1972-1973/2008) escreve como S(A) e lê-se significante da falta no grande Outro. Essa falta remete ao irrepresentável, e aponta a impossibilidade da linguagem, do significante circunscrever todo o real.

É nesse ponto que Lacan define o feminino, campo aberto a homens e mulheres enquanto pertencentes a um ou outro sexo, mas que marca de maneira particular uma mulher, pois na constituição da feminilidade ela necessariamente é confrontada com essa condição de não ser de todo inscrita na lógica fálica. Daí ele dizer que "elas não sabem o que dizem", sendo não todas em relação ao gozo da função fálica, extraíndo daí um gozo suplementar (p. 79). 
Isso não coloca uma mulher fora da função fálica, pois ela está nela de todo, apesar de ser não toda. As tábuas da sexuação colocam em evidência mais uma vez a duplicidade feminina ao indicar que uma mulher se divide entre o gozo fálico e "um gozo para além do falo" (p. 80). Essa dupla possibilidade sacode e/ou acode as mulheres, como brinca Lacan.

Recuperando a etimologia desses verbos, sacudir e acudir, podemos ver que um se opõe ao outro apenas pelo prefixo. Enquanto acudir tem, entre vários significados, o de suprir, responder ao chamado, atender, auxiliar, solucionar; sacudir, além de outros significados, indica pôr abaixo, deitar abaixo, fazer cair. Então parece que é dessa ordem a loucura feminina: algo as faz cair, as sacode, mas também algo as acode, as auxilia. $\mathrm{O}$ fazer cair, próprio às sacudidas a que são submetidas, lançam-nas na experiência do fora de sentido, e é nisso que as mulheres neuróticas podem frequentar esse campo em que falta um significante no Outro, aproximando-as da experiência psicótica, em que o sentido não se sustenta na amarração fálica. Brincando com os significantes da álgebra lacaniana, podemos dizer que no feminino algo $S(\mathbb{A})$ code, podendo incitar à loucura.

Sofrer das sacudidas e ao mesmo tempo encontrar apoio em algo que acode faz com que não se possa dizer universalmente que todas as mulheres são loucas. Lacan (1974/2003b), encontra nos gozos que dividem uma mulher um modo de responder a questão freudiana acerca do desejo feminino, "assim, o universal do que elas desejam é a loucura: todas as mulheres são loucas, como se diz. É por isso mesmo que são não todas, isto é, não loucas-de-todo" (p. 538).

O modo como cada uma dessas não loucas-de-todo frequenta o gozo para além do falo é singular e muitas vezes é fadado aos efeitos do recalque. Por isso a declaração que algumas fazem de que se ressentem de não cometer as desejadas loucuras, o que muitas vezes as enterra no sintoma histérico, preponderantemente fálico. Esses sujeitos parecem recear perder-se no lugar sem lei, enlouquecer de vez, daí se agarram ao lugar fálico defendendo-se de uma entrega ao feminino, temido e desejado. Se há medo de enlouquecer, há também desejo de ir além, ainda que não de todo. O gozo fálico não é suficiente para impedir totalmente a possibilidade das mulheres se portarem como loucas, ora jogando histericamente, ora sendo mesmo atravessadas pelo que as sacode, pela loucura da qual sequer podem dizer.

O desejo de cometer loucuras talvez indique certo vislumbre que as mulheres fazem de que há algo além dos limites do recalque, este que normaliza, impondo um modo masculino de funcionar ao desejo. É esse o jogo de palavras que pode ser feito com a normalidade masculina em francês (Lacan, 1972/2003a). Escapar à norme mâle (norma masculina) é frequentar 


\section{ARTIGOS}

esse lugar fora da lei, tão próprio aos que foram estruturalmente sacudidos, os psicóticos.

\section{Referências}

Freud, S. (1976a). Casos clínicos. In Edição Standard Brasileira das Obras Psicológicas Completas de Sigmund Freud (Vol. II). Rio de Janeiro: Imago. (Trabalho original publicado em 1893-1895).

Freud, S. (1976b). Fantasias histéricas e sua relação com a bissexualidade. In Edição Standard Brasileira das Obras Psicológicas Completas de Sigmund Freud (Vol. IX). Rio de Janeiro: Imago. (Trabalho original publicado em 1908).

Freud, S. (1976c). Notas sobre um caso de neurose obsessiva. In Edição Standard Brasileira das Obras Psicológicas Completas de Sigmund Freud (Vol. X). Rio de Janeiro: Imago. (Trabalho original publicado em 1909).

Freud, S. (1976d). A organização genital infantil: uma interpolação na teoria da sexualidade. In Edição Standard Brasileira das Obras Psicológicas Completas de Sigmund Freud (Vol. XIX). Rio de Janeiro: Imago. (Trabalho original publicado em 1923).

Freud, S. (1976e). A dissolução do complexo de Édipo. In Edição Standard Brasileira das Obras Psicológicas Completas de Sigmund Freud (Vol. XIX). Rio de Janeiro: Imago. (Trabalho original publicado em 1924c).

Freud, S. (1976f). Sexualidade feminina. In Edição Standard Brasileira das Obras Psicológicas Completas de Sigmund Freud (Vol. XXI). Rio de Janeiro: Imago. (Trabalho original publicado em 1931).

Freud, S. (1976g). Feminilidade. In Edição Standard Brasileira das Obras Psicológicas Completas de Sigmund Freud (Vol. XXII). Rio de Janeiro: Imago. (Trabalho original publicado em 1933[1932]).

Freud, S. (2007a). Neurose e psicose. In Escritos sobre a psicologia do inconsciente (Vol. III). Rio de Janeiro: Imago, 2007. (Trabalho original publicado em 1924).

Freud, S. (2007b). A perda da realidade na neurose e na psicose. In Escritos sobre a psicologia do inconsciente (Vol. III). Rio de Janeiro: Imago, 2007. (Trabalho original publicado em 1924).

Lacan, J. (1998a). Formulações sobre a causalidade psíquica. In Escritos. Rio de Janeiro: Jorge Zahar. (Trabalho original publicado em 1946).

Lacan, J. (1998). De uma questão preliminar a todo tratamento possível da psicose. In Escritos. Rio de Janeiro: Jorge Zahar. (Trabalho original publicado em 1959).

Lacan, J. (2002). O seminário. Livro 3. As psicoses. Rio de Janeiro: Jorge Zahar. (Trabalho original publicado em 1955-1956). 
Lacan, J. (1995). O Seminário, livro 4. A relação de objeto. Rio de Janeiro: Jorge Zahar. (Trabalho original publicado em 1956-1957).

Lacan, J. (1999). O Seminário. Livro 5. As formações do inconsciente. Rio de Janeiro: Jorge Zahar,1999. (Trabalho original publicado em 1957-1958).

Lacan, J. (1998). De uma questão preliminar a todo tratamento possível da psicose. In Escritos. Rio de Janeiro: Jorge Zahar. (Trabalho original publicado em 1959).

Lacan, J. (1998). Diretrizes para um congresso sobre a sexualidade feminina. Em: Escritos, Rio de Janeiro: Zahar. (Trabalho original publicado em 1960).

Lacan, J. (2003a). O Aturdito. In Outros Escritos. Rio de Janeiro: Zahar. (Trabalho original publicado em 1973).

Lacan, J. (2003b). Televisão. In Outros Escritos. Rio de Janeiro: Zahar. (Trabalho original publicado em 1974).

Lacan, J. (2005). O seminário. Livro 10. A angústia. Rio de Janeiro: Zahar. (Trabalho original publicado em 1962-1963).

Lacan, J. (2008). O Seminário. Livro 20. Mais, ainda. Rio de Janeiro, Zahar. (Trabalho original publicado em 1972-1973).

Maurano, D. (2011). Torções: a psicanálise, o barroco e o Brasil. Curitiba, PR: CRV.

\section{Resumos}

(The neighborhoods between femininess and madness)

The topic of female madness often presents itself in psychoanalysis by means of neurotic subjects. In this article, we question the vicinity between psychosis and madness that presents itself in the speech of neurotic women. Initial identifications, whereby children alienate themselves to the desire of the Other, determine a certain madness, not restricted only to the psychotic. To a female subject, who lives through the tortuous process of becoming a woman, madness is a possibility, since a woman, find herself torn between masculine and feminine pleasure, approaches madness, but is not completely mad.

Key words: Female madness, psychosis, phallic pleasure, feminine pleasure

(Rapprochements entre le féminin et la folie)

Le thème de la folie féminine se présente souvent dans la clinique psychanalytique par l'intermédiaire de sujet névrosés. On remet en question dans cet article les rapprochements entre la psychose et la folie retrouvés dans le discours de femmes névrosées. Les identifications initiales par lesquelles l'enfant est aliéné au désir de l'Autre déterminent une certaine folie aucunement restreinte qu' aux psychotiques. 


\section{ARTIGOS}

Pour un sujet féminin qui connaît le processus tortueux de devenir femme, la folie représente une issue, du fait qu'une femme, se retrouvant partagée entre la jouissance masculine et la féminine, se rapproche de la folie, mais est loin d'être complètement folle.

Mots clés: Folie féminine, psychose, jouissance phallique, jouissance féminine

(De las vecindades entre lo feminino y la locura)

El tema de la locura femenina se presenta a menudo en la práctica psicoanalítica a través de sujetos neuróticos. En este artículo, se cuestiona la cercanía entre la psicosis y la locura que se presenta en el discurso de las mujeres neuróticas. Las identificaciones iniciales, a través de las cuales el niño se aliena al deseo del Otro, determinan un cierto grado de locura, que no se restringe solamente a los psicóticos. Para un sujeto del sexo femenino, que atraviesa por el tortuoso proceso de convertirse en mujer, la locura es una posibilidad, ya que la mujer, al verse divida entre el gozo masculino y el femenino, se acerca a la locura, pero no es loca del todo.

Palabras clave: Locura femenina, psicosis, goce fálico, goce femenino

(Das Verwandtschaftsverhältnis zwischen dem Weiblichen und dem Wahnsinn)

Das Thema des weiblichen Wahnsinns wird in der psychoanalytischen Klinik oft durch neurotische Subjekte beigetragen. Dieser Artikel untersucht das Verwandtschaftsverhältnis zwischen der Psychose und dem Wahnsinn, der sich in den Aussagen von neurotischen Frauen manifestiert. Die ursprünglichen Identifikationen, durch welche das Kind sich vom Wunsch des Anderen entfremdet, bestimmen einen bestimmten Grad des Wahnsinns, der sich nicht nur auf die psychotischen Subjekte beschränkt. Für das weibliche Subjekt, welches den qualvollen Prozess des Frau-werdens erleidet, ist der Wahnsinn eine Möglichkeit, da eine Frau, die zwischen dem männlichen und dem weiblichen Geniessen schwankt, sich zwar dem Wahnsinn nähert, aber nicht total verrückt wird.

Schlüsselwörter: Weiblicher Wahnsinn; Psychose; phallisches Geniessen; weibliches Geniessen.

Schlüsselwörter: Weiblicher Wahnsinn, Psychose, phallisches Geniessen, weibliches Geniessen

(邻里之间女性和疯狂的)

女疯狂的主题往往呈现在精神分析诊所, 通过主题结构神经质。在这个 问题第条精神病与神经质妇女的演讲中提出自己的疯狂附近。初步鉴定, 藉以 孩子疏远了对方的欲望, 如果确定某些疯狂, 不仅限于精神病。对主题属于女 性, 通过曲折的过程, 成为一名女子, 疯狂是一种可能性, 作为一个女人, 发 现自己左右为难, 男性和女性, 接近疯狂, 但它并不是疯狂的全部。 关键词: 女性疯狂, 精神病, 阳具的欢爽, 女性的欢爽。 
Citação/Citation: Landi, E. C., Carvalho, I. S., Chatelard, D. S. (2016, dezembro). Das vizinhanças entre o feminino e a loucura. Revista Latinoamericana de Psicopatologia Fundamental, 19(4), 663-677.

Editores do artigo/Editors: Profa. Dra. Ana Maria Rudge Profa. Dra. Sonia Leite

Recebido/Received: 13.8.2015/ 8.13.2015 Aceito/Accepted: 21.10.2015 / 10.21.2015

Copyright: (C) 2009 Associação Universitária de Pesquisa em Psicopatologia Fundamental/ University Association for Research in Fundamental Psychopathology. Este é um artigo de livre acesso, que permite uso irrestrito, distribuição e reprodução em qualquer meio, desde que o autor e a fonte sejam citados / This is an open-access article, which permits unrestricted use, distribution, and reproduction in any medium, provided the original authors and sources are credited.

Financiamento/Funding: As autoras declaram não ter sido financiadas ou apoiadas / The authors have no support or funding to report.

Conflito de interesses/Conflict of interest: As autoras declaram que não há conflito de interesses / The authors have no conflict of interest to declare.

\section{Elizabeth Cristina Landi}

Psicanalista; Membro do Corpo Freudiano Escola de Psicanálise Seção Goiânia (Goiânia, GO, Br); Doutoranda do Programa de Pós-Graduação em Psicologia Clínica e Cultura da Universidade de Brasília (UnB) (Brasília, DF, Br); Docente da Universidade Federal de Goiás (UFG) (Goiânia, GO, Br) e da Pontifícia Universidade Católica de Goiás (PUC-Goiás) (Goiânia, GO, Br).

Rua 115-A, n. 97, Setor Sul 74085-250 Goiânia, GO, Br elizabethclandi@gmail.com

\section{Isalena Santos Carvalho}

Psicóloga; Membro da Escola de Psicanálise do Maranhão (São Luiz, MA, Br); Doutorado em Psicologia Clínica e Cultura pela Universidade de Brasília (UnB) (Brasília, DF, Br); Docente da Graduação e da Pós-Graduação em Psicologia da Universidade Federal do Maranhão (São Luiz, MA, Br).

Av. dos Portugueses, s/n. - Bacanga

Campus do Bacanga, Centro de Ciências Humanas, Departamento de Psicologia 65085-580 São Luís, MA, Br

isalenasc@yahoo.com.br 


\section{ARTIGOS}

\section{Daniela Sheinkman Chatelard}

Psicanalista; Membro da Escola dos Fóruns do Campo Lacaniano; Docente do Programa de Pós-Graduação em Psicologia Clínica e Cultura da Universidade de Brasília (UnB) (Brasília, $\mathrm{DF}, \mathrm{Br})$.

SQN $206 \mathrm{~J} 105$

70844-100 Brasília, DF, Br

dchatelard@gmail.com

This is an open-access article, which permits unrestricted use, distribution, and reproduction in any medium for non-commercial purposes provided the original authors and sources are credited.

Rev. Latinoam. Psicopat. Fund., São Paulo, 19(4), 663-677, dez. 2016 